\title{
Identificação molecular e suscetibilidade antifúngica de Candida parapsilosis isoladas no Ceará, Brasil
}

Primeira submissão em 15/11/11 Última submissão em 28/09/12 Aceito para publicação em 07/10/12 Publicado em 20/12/12

\section{Molecular identification and antifungal susceptibility of Candida parapsilosis isolates in Ceará, Brazil}

Everardo Albuquerque Menezes'; Antônio Alexandre de Vasconcelos Júnior²; Francisco Afrânio Cunha; Maria Conceição dos Santos Oliveira Cunha4; Bárbara Helena Lima Braz; ; Ligya Guimarães Capelo5; Carlla Lorena Façanha Silva ${ }^{6}$

\section{unitermos \\ Candida parapsilosis \\ Antifúngicos \\ Identificação molecular}

\section{resumo}

Introdução: Candida parapsilosis é a segunda ou terceira levedura mais isolada de hemoculturas em várias partes do mundo. É um patógeno comumente isolado no Brasil e no Ceará. Apresenta capacidade de formar biofilmes em cateteres e outros dispositivos médicos e esses fatores contribuem para a disseminação dessa levedura. Objetivos: Identificar e avaliar a suscetibilidade aos antifúngicos de $C$. parapsilosis isoladas de amostras de sangue e urina de pacientes atendidos em hospitais no Ceará. Métodos: Foram isoladas e identificadas 57 cepas de C. parapsilosis. As cepas foram identificadas por testes fenotípicos e moleculares. A suscetibilidade foi avaliada pelo método de microdiluição em caldo (protocolo do Clinical and Laboratory Standards Institute [CLSI] M27-A3). Foram avaliados cinco antifúngicos (anfotericina B, caspofungina, fluconazol, itraconazol e voriconazol). Resultados e conclusão: As cepas foram identificadas como C. parapsilosis por testes fenotípicos e confirmadas pelos testes moleculares. Quanto ao perfil de sensibilidade, elas se mostraram sensíveis aos antifúngicos testados, sendo a resistência ainda um fenômeno raro entre cepas de C. parapsilosis isoladas no Ceará.

\section{abstract}

Introduction: C. parapsilosis is the second or third most isolated yeast from blood cultures in various parts of the world. It is a commonly isolated pathogen in Brazil and Ceará. C. parapsilosis is liable to form biofilms on catheters and other medical devices, which contributes to the spread of this yeast. Objective: The objective of this study was to identify and assess the antifungal susceptibility of C. parapsilosis isolates from blood and urine samples collected from patients in hospitals in Ceará. Methods: We isolated and identified 57 strains of C. parapsilosis. The strains were identified by phenotypic and molecular tests. The susceptibility to antifungals was assessed by broth microdilution (Clinical and Laboratory Standards Institute [CLSI] protocol M27A3). We tested five antifungals (amphotericin B, caspofungin, fluconazole, itraconazole and voriconazole). Results and conclusion: The strains were identified as C. parapsilosis by phenotypic tests and confirmed by molecular tests. As to the sensitivity profile, the strains were sensitive to the antifungal agents, hence resistance is still a rare phenomenon among $\mathrm{C}$. parapsilosis isolates in Ceará. key words

Candida parapsilosis

Antifungals

Molecular identification

\footnotetext{
1. Doutor em Ciências Biológicas (Microbiologia) pela Universidade de São Paulo (USP); professor e pesquisador do Departamento de Análises Clínicas e Toxicológicas da Universidade Federal do Ceará (UFCE)

2. Graduação em Farmácia pela UFCE; mestrando em Microbiologia e Parasitologia pela Universidad Complutense de Madrid.

3. Mestre em Ciências e Tecnologia de Alimentos pela UFCE; pesquisador do Departamento de Análises Clínicas e Toxicológicas da UFCE.

4. Especialista em Vigilância Sanitária de Alimentos pela Universidade Estadual do Ceará.

5. Graduação em Ciências Biológicas pela Universidade Estadual Vale do Acaraú.

6. Graduanda em Química Industrial pela UFCE.
} 


\section{Introdução}

Infecções fúngicas, principalmente causadas por leveduras do gênero Candida, são cada vez mais comuns em pacientes imunodeprimidos ou nos que foram submetidos a regimes terapêuticos especiais. Essas infecções fúngicas apresentam um custo hospitalar elevado, pois aumentam o tempo de internação do paciente, além de causarem elevada mortalidade ${ }^{(1,19)}$.

A principal levedura isolada de infecções fúngicas ainda é C. albicans, no entanto, C. parapsilosis tem emergido nos últimos anos, sendo um isolado comum em candidemias, sobretudo em alguns grupos de pacientes, como neonatos e transplantados, além disso, em indivíduos recebendo nutrição parenteral, é mais prevalente que C. albicans ${ }^{(1,3,13,21,22,28,29)}$. C. parapsilosis é a segunda espécie mais isolada em amostras de candidemia em muitas regiões do mundo. Esse aumento da sua incidência de isolados tem sido explicado, em parte, por sua considerável capacidade de formar biofilme e, portanto, alta afinidade com dispositivos intravasculares $\mathrm{e}$ de nutrição parenteral $(3,14,15,28)$.

Surtos hospitalares causados por C. parapsilosis têm sido descritos com frequência e as principais fontes de infecção encontradas foram as mãos dos profissionais de saúde, as infusões, os biomateriais, entre outros ${ }^{(3,26)}$.

Nos últimos anos, C. parapsilosis vem sendo isolada em diversos estudos realizados no Ceará, Nordeste do Brasil $^{(12,15,16,30)}$. O objetivo do nosso estudo foi identificar e avaliar, por métodos fenotípicos e moleculares, a suscetibilidade dessa levedura aos antifúngicos anfotericina $B$, caspofungina, fluconazol, itraconazol e voriconazol de amostras isoladas desse estado brasileiro.

\section{Materiais e métodos}

\section{Origem das cepas}

Neste estudo, foram utilizadas 57 cepas de C. parapsilosis isoladas de amostras de sangue (49) e urina (8) oriundas de pacientes atendidos em Hospitais do Ceará. Essas leveduras foram cedidas pelo Laboratório Central de Saúde Pública do Ceará (LACEN-CE) e fazem parte da coleção do Laboratório de Microbiologia de Leveduras do Departamento de Análises Clínicas da Universidade Federal do Ceará (UFCE). Elas estavam estocadas em tubos eppendorf, contendo meio triptona soja caldo com $50 \%$ de glicerol e armazenadas a $-20^{\circ} \mathrm{C}$.

\section{Identificação bioquímica e micromorfologia de C. parapsilosis}

As cepas foram descongeladas, semeadas em ágar Sabouraud-glucose e incubadas a $35^{\circ} \mathrm{C}$ por $24-48$ horas. Após o crescimento, as leveduras foram semeadas em meio cromógeno e incubadas a $35^{\circ} \mathrm{C}$ por $24-48$ horas, com o objetivo de garantir a pureza dos isolados. Nas cepas sugestivas de C. parapsilosis, foram realizadas as técnicas manuais e convencionais de fermentação, assimilação de carboidratos e micromorfologia em ágar arroz com tween $80^{(12,16,22,30)}$.

\section{Identificação molecular de C. parapsilosis}

A confirmação definitiva das cepas de C. parapsilosis foi realizada por métodos moleculares. $O$ primeiro passo na identificação foi a extração do ácido desoxirribonucleico (DNA). Brevemente, foram retiradas cinco colônias de crescimento recente e inoculadas em tubos de eppendorf contendo $0,5 \mathrm{ml}$ de tampão de extração $(50 \mathrm{mM}$ de tris hidrocloreto [Tris-HCl], $50 \mathrm{mM}$ de ácido etilenodiaminotetracético [EDTA], 3\% de dodecil sulfato de sódio [SDS] e $1 \%$ de 2-mercaptanol), sendo, posteriormente, incubadas a $100^{\circ} \mathrm{C}$ por 30 minutos. Após o aquecimento, os eppendorfs foram colocados a $-20^{\circ} \mathrm{C}$ por 30 minutos. O lisado foi extraído acrescentando $0,5 \mathrm{ml}$ da solução fenol-clorofórmio-álcool isoamílico $(25 / 24 / 1 \mathrm{v} / \mathrm{v} / \mathrm{v})$. O sobrenadante foi transferido para um eppendorf esterilizado e adicionou-se $65 \mu \mathrm{l}$ da solução de acetato de sódio $3 \mathrm{M}$ e 75 $\mu \mathrm{l}$ de cloreto de sódio $1 \mathrm{M}$. O DNA foi precipitado com igual volume de isopropanol absoluto gelado e centrifugado a $10.000 \mathrm{~g}$ durante 30 minutos. Após, foi lavado três vezes com etanol gelado a $70 \%$ e centrifugado a $5.000 \mathrm{~g}$ durante 5 minutos. O DNA foi diluído em $0,5 \mathrm{ml}$ de água destilada e armazenado em geladeira a $4^{\circ} \mathrm{C}$ até o momento da reação em cadeia da polimerase (PCR). Para a confirmação da identificação das cepas de C. parapsilosis, utilizamos os primers do alcohol dehydrogenase-encoding gene (SADH) (S1F, 5'-GTT GAT GCT GTT GGA TTG-3') e (S1R, 5'-CAA TGC CAA ATC TCC CAA- $3^{\prime}$ ) e as condições da $\mathrm{PCR}$ foram $95^{\circ} \mathrm{C}$ por 5 minutos, seguidos de 40 ciclos de $92^{\circ} \mathrm{C}$ por 1 minuto, $45^{\circ} \mathrm{C}$ por 1 minuto e $68^{\circ} \mathrm{C}$ por 1 minuto; a extensão foi realizada a $72^{\circ} \mathrm{C}$ por 7 minutos ${ }^{(14,24)}$.

As amplificações foram realizadas para um volume final de $50 \mu \mathrm{l}$. A PCR foi realizada no termociclador Biocicler ${ }^{\circledR}$ (Biosystems). Como controles para confirmar a identificação, foram utilizadas as cepas C. albicans ATCC 10231 e C. albicans ATCC 14053. Após a PCR, os fragmentos de DNA 
foram submetidos a eletroforese $3 \mathrm{v} / \mathrm{cm}$, durante 3 horas, em tampão Tris-Borato-EDTA (TBE) $0,5 \times$ (Tris $\mathrm{HCl} 5,4 \mathrm{~g}$; ácido bórico 2,75 g; EDTA $5 \mathrm{M} 2 \mathrm{ml}$, pH 8; e $1.000 \mathrm{ml}$ de água). Após a eletroforese, os fragmentos de DNA foram visualizados em gel de agarose $2 \%$ corado com brometo de etídio. Para avaliar o tamanho do fragmento de DNA amplificado, foi utilizado o marcador de peso molecular $\lambda /$ Hind III.

\section{Teste de suscetibilidade a antifúngicos (TSA)}

A sensibilidade aos antifúngicos anfotericina $B$ (Inlab-SP), fluconazol (Sigma-EUA), itraconazol (Sigma-EUA), caspofungina (Merck-EUA) e voriconazol (Sigma-EUA) foi testada pelo método de microdiluição em caldo (MDC) em meio Roswell Park Memorial Institute (RPMI), como recomenda o protocolo do Clinical and Laboratory Standards Institute (CLSI) M27-A3; utilizou-se RPMI caldo tamponado com ácido morfolino polissulfônico (MOPS). A anfotericina $B$ foi solubilizada em dimetilsulfóxido e os outros antifúngicos, em água. A faixa testada para a anfotericina $B$, caspofungina, itraconazol e voriconazol variou de 16 a $0,03 \mu \mathrm{g} / \mathrm{ml}$ e o fluconazol de 64 a $0,25 \mu \mathrm{g} / \mathrm{ml}$. As placas foram inoculadas com as cepas e incubadas a $35^{\circ} \mathrm{C}$ por 24-48 horas. Decorrido esse período, foi realizada a leitura visual delas.

A concentração inibitória mínima (MIC) da anfotericina $B$ foi aquela na qual não ocorreu crescimento fúngico; para os azólicos e a caspofungina, foi observada a concentração de antifúngico que causou redução de $50 \%$ e $90 \%$ do crescimento, quando comparados com o controle . $O$ experimento foi realizado em três repetições. $O$ controle de qualidade dos testes foi realizado com as cepas $C$. parapsilosis ATCC 22019 e C. krusei ATCC 6258 $(7,8,10)$.

\section{Critérios interpretativos das MICs}

A interpretação das MICs para a MDC foi realizada de acordo com o protocolo M27-S3:

- anfotericina B - sensível $(\mathrm{S}), \mathrm{MIC}<1 \mu \mathrm{g} / \mathrm{ml}$; resistente (R), MIC $>1 \mu \mathrm{g} / \mathrm{ml}$.

- Fluconazol - S, MIC $\leq 8 \mu \mathrm{g} / \mathrm{ml}$; sensível dose-dependente (SDD), MIC 16 a $32 \mu \mathrm{g} / \mathrm{ml}$; R, MIC $\geq 64 \mu \mathrm{g} / \mathrm{ml}$.

- Caspofungina - S, MIC $<4 \mu \mathrm{g} / \mathrm{ml} ; \mathrm{R}, \mathrm{MIC}>4 \mu \mathrm{g} / \mathrm{ml}$.

- Itraconazol e voriconazol - $\mathrm{S}, \mathrm{MIC} \leq 2 \mu \mathrm{g} / \mathrm{ml}$; SDD, MIC 16 a $32 \mu \mathrm{g} / \mathrm{ml} ; \mathrm{R}, \mathrm{MIC} \geq 16 \mu \mathrm{g} / \mathrm{ml}^{(7,8,10)}$.

\section{Resultados}

A identificação de C. parapsilosis utilizando o meio cromógeno ainda é um pouco complicada devido à dificuldade da leitura; a cor rosa claro apresentada é comum a outras espécies de Candida.

Em nosso trabalho todas as cepas testadas foram identificadas como C. parapsilosis pelo meio cromógeno em associação aos métodos bioquímicos e moleculares. Quanto ao TSA, foram avaliados cinco antifúngicos sistêmi$\cos$ (anfotericina B, caspofungina, fluconazol, itraconazol e voriconazol). Os valores das MICs para o fluconazol foram os mais elevados, com intervalo entre 0,125 e $16 \mu \mathrm{g} / \mathrm{ml}$, apresentando médias geométricas maiores que as dos demais antifúngicos testados, com variação de 0,24 a 0,69 $\mu \mathrm{g} / \mathrm{ml}$. No entanto, os resultados para o voriconazol foram os mais baixos, com os valores da MIC mais baixos e as médias geométricas variando entre 0,03 e 0,06 $\mu \mathrm{g} / \mathrm{ml}$ (Tabela).

Para as cepas de C. parapsilosis avaliadas, observou-se que a resistência ainda é incomum, como pode ser

\section{Tabela Sensibilidade in vitro a antifúngicos de $C$. parapsilosis}

\begin{tabular}{|c|c|c|c|c|c|}
\hline \multirow[t]{2}{*}{ Levedura (n) } & \multicolumn{5}{|c|}{ Antifúngicos ( $\mu g / m l)$} \\
\hline & Anfotericina B & Caspofungina & Fluconazol & Itraconazol & Voriconazol \\
\hline \multicolumn{6}{|l|}{ C. parapsilosis (57) } \\
\hline Intervalo MIC & $\leq 0,03-2$ & $\leq 0,015-1$ & $\leq 0,125-16$ & $\leq 0,03-0,5$ & $\leq 0,03-1$ \\
\hline \multicolumn{6}{|c|}{ Média geométrica dos MICs de todas as cepas testadas } \\
\hline $\mathrm{MIC}_{50} 24 \mathrm{~h}(\mu \mathrm{g} / \mathrm{ml})$ & 0,11 & 0,10 & 0,24 & 0,03 & 0,03 \\
\hline $\mathrm{MIC}_{50} 48 \mathrm{~h}(\mu \mathrm{g} / \mathrm{ml})$ & 0,23 & 0,13 & 0,41 & 0,05 & 0,04 \\
\hline $\mathrm{MIC}_{90} 24 \mathrm{~h}(\mu \mathrm{g} / \mathrm{ml})$ & - & 0,14 & 0,39 & 0,04 & 0,04 \\
\hline $\mathrm{MIC}_{90} 48 \mathrm{~h}(\mu \mathrm{g} / \mathrm{ml})$ & - & 0,24 & 0,69 & 0,06 & 0,06 \\
\hline
\end{tabular}

MIC: concentração inibitória mínima. 
evidenciado na Tabela. As médias geométricas das MICs encontradas para todos os antifúngicos foram extremamente baixas, evidenciando a sensibilidade.

\section{Discussão}

C. parapsilosis apresenta capacidade de formar biofilmes em cateteres e outros dispositivos médicos. Esses fatores contribuem para a disseminação e a permanência dessa levedura em ambiente hospitalar(28). Essas são razões que tornam sua identificação essencial.

Os isolamentos primários de leveduras de amostras clínicas são realizados em meio ágar Sabouraud glucose ou ágar batata dextrose, meios que não permitem a identificação das espécies. A identificação é realizada por uma série de testes adicionais que envolvem fermentação e assimilação de açúcares e os resultados não são liberados pelo laboratório em menos de 48 horas. Como esses testes podem levar vários dias para dar o resultado, o uso de meios cromógenos disponíveis pode ajudar a reduzir o tempo para isolamento, além de detectar a presença de culturas mistas ${ }^{(9)}$.

CHROMagar Candida ${ }^{\circledR}$ é um meio seletivo e diferencial, que é utilizado para uma rápida e presuntiva identificação e diferenciação de espécies de Candida isoladas de amostras clínicas. A diferenciação das espécies é baseada na coloração e na morfologia. A incorporação de substratos cromógenos foi um grande avanço na identificação laboratorial de leveduras, pois permite observar se a amostra clínica possui mais de uma levedura, possibilitando a provável identificação delas, e direciona na escolha do tratamento antifúngico a ser estabelecido ${ }^{(2,23)}$. Apesar de apresentar resultados seguros para muitas espécies de leveduras, a identificação utilizando somente meio cromógeno não é suficiente, uma vez que podem ocorrer resultados duvidosos, conforme apresentado em nosso trabalho, sendo, portanto, necessários outros testes para confirmar a identificação das cepas, bem como pessoal treinado para esse procedimento nos laboratórios Clínicos $^{(30)}$. Os testes de biologia molecular poderiam auxiliar ainda mais nesse diagnóstico, liberando um resultado mais seguro para o paciente para que seja instalada a terapêutica adequada ${ }^{(5)}$.

O complexo Parapsilosis é composto por três espécies (C. parapsilosis, C. metapsilosis e C. orthopsilosis); a diferenciação fenotípica somente é possível utilizando biologia molecular ${ }^{(14,24,25,31)}$. No nosso estudo fizemos a amplificação do gene SADH específico do complexo C. parapsilosis, mas não foi possível fazer a diferenciação das espécies devido a falta da enzima Banl, etapa que será realizada futuramente.
Em um trabalho recente com 114 complexos C. parapsilosis isoladas de amostras clínicas no Kuwait, foram identificadas 109 C. parapsilosis, cinco C. orthopsilosis e nenhuma C. metapsilosis( ${ }^{(4)}$. Em outro relato cientíicico com 79 amostras de C. parapsilosis, foi possível identificar todas as amostras com os mesmos primers utilizados em nosso estudo ${ }^{(17)}$. Toro et al. identificaram 122 cepas utilizando essa mesma técnica ${ }^{(27)}$.

No que se refere ao perfil de suscetibilidade, diversos antifúngicos, incluindo os azólicos, os poliênicos, as flucitosinas e as equinocandinas, apresentam atividade contra cepas de C. parapsilosis isoladas de infecções ${ }^{(6)}$.

Observa-se na Tabela que todos os antifúngicos testados apresentaram atividade contra C. parapsilosis. Não foi detectada nenhuma cepa resistente aos antifúngicos testados. O voriconazol apresentou MICs consideravelmente baixas para a C. parapsilosis; já a caspofungina foi ativa, mas os resultados das MICs foram mais dispersos, além de médias geométricas maiores.

Considerando-se os antifúngicos testados, o fluconazol foi o que apresentou menor atividade, pois a média geométrica foi a mais elevada. Entretanto, percebe-se que todas as cepas são sensíveis. Em um estudo com 39 cepas de C. parapsilosis, não se observou resistência ao voriconazol ou à caspofungina ${ }^{(18)}$.

Cepas de C. parapsilosis são menos sensíveis a caspofungina que outras Candida spp. devido a uma mutação genética que pode conferir tolerância ${ }^{(20)}$. No nosso trabalho, a caspofungina apresentou médias geométricas um pouco mais elevadas, o que pode ser resultado dessa tolerância. Essa estranha relação entre caspofungina e C. parapsilosis necessita de maiores investigações.

Em um estudo realizado com 118 cepas de C. parapsilosis, não foi observada resistência à caspofungina e ao voriconazol ${ }^{(20)}$, resultados semelhantes aos encontrados no nosso estudo. A sensibilidade de 39 C. parapsilosis foi realizada na Espanha e não se detectou resistência a caspofungina nem ao voriconazol ${ }^{(11)}$. Como podemos observar, os resultados do nosso trabalho são semelhantes aos encontrados em outros locais do mundo, apesar de não ter sido detectada resistência; a monitoração deve ser mantida continuamente.

Em um estudo com 25 cepas de C. parapsilosis, a resistência ao fluconazol não foi detectada(26). Esta é caracterizada pela presença de MIC > $64 \mu \mathrm{g} / \mathrm{ml}$. Neste estudo, não foram detectadas essas MICs, no máximo as cepas exibiram $\mathrm{MIC}=16 \mu \mathrm{g} / \mathrm{ml}$, o que caracteriza a SDD, conforme apresentado na Tabela. 


\section{Conclusão}

Estudos envolvendo a identificação e a avaliação da suscetibilidade aos antifúngicos de leveduras do gênero Candida, sobretudo de C. parapsilosis, são muito importantes. No presente trabalho, não encontramos cepas resistentes aos antifúngicos. Mesmo sabendo que a resistência ainda é um fenômeno raro entre essas cepas, a identificação e a monitoração do perfil de suscetibilidade são fundamentais para evitar a disseminação da resistência.

\section{Agradecimentos}

Ao Conselho Nacional de Desenvolvimento Científico e Tecnológico (CNPq) e à Fundação Cearense de Apoio a Pesquisa (Funcap).

\section{Referências}

1. ALANGADEN, G. J. Nosocomial fungal infections: epidemiology, infection control, and prevention. Infect Dis Clin N Am, v. 25, n. 1, p. 201-25, 2011.

2. ALFONSO, C. et al. Identificación presuntiva de Candida spp. y de otras levaduras de importância clínica: utilidad de brilliance Candida agar. Rev Iberoam Micol, v. 27, n. 2, p. 90-3, 2010.

3. ALMIRANTE, B. et al. Epidemiology, risk factors, and prognosis of Candida parapsilosis bloodstream infections: case-control population-based surveillance study of patients in Barcelona, Spain, from 2002 to 2003. J Clin Microbiol, v. 44, n. 5, p. 1681-5, 2006

4. ASADZADEH, M. et al. Rapid molecular differentiation and genotypic heterogeneity among Candida parapsilosis and Candida orthopsilosis strains isolated from clinical specimens in Kuwait. J Medical Microbiol, v. 58, n. 1. p. 745-52, 2009.

5. BASKOVA, L. et al. The Pan-AC assay: a single-react ion real-time PCR test for quantitative detection of a broad range of Aspergillus and Candida species. J Med Microbiol, v. 56, n. 1, p. 1167-73, 2007.

6. CAPPELLETTY, D.; EISELSTEIN-MCKITRICK, K. The echinocandins. Pharmacother, v. 27, n. 4, p. 369-88, 2007.

7. CLINICAL AND LABORATORY STANDARDS INSTITUTE. Reference method for broth dilution antifungal susceptibility testing of yeasts. Approved standard M27-A3. 3. ed. Clinical and Laboratory Standards Institute, Wayne, PA. 2008a.

8. CLINICAL AND LABORATORY STANDARDS INSTITUTE. Reference method for broth dilution antifungal susceptibility testing of yeasts. $3^{\text {rd }}$ informational supplement, M27-S3. Clinical and Laboratory Standards Institute, Wayne, PA. 2008b.

9. ERASO, E. et al. Evaluation of the new chromogenic medium Candida ID 2 for isolation and identification of Candida albicans and other medically important Candida species. J Clin Microbiol, v. 44, n. 9, p. 3340-5, 2006.

10. ESPINEL-INGROFF, A.; CANTÓN, E. Antifungal susceptibility testing of yeasts. In: SCHWALBE, R.; STEELEMOORE, L.; GOODWIN, A. C. (Eds.). Antimicrobial susceptibility testing protocols. Boca Raton, Flórida: CRC Press, 2007. Cap. 9, p. 173-208.
11. FLÓREZ, J. A. et al. In vitro susceptibilities of bloodstream isolates of Candida spp.: results from a multicenter active surveillance program in Andalusia. Enferm Infecc Microbiol Clin, v. 27, n. 9 p. 518-20, 2009.

12. GOMES, C. L. et al. Identificação e perfil de sensibilidade de Candida spp. isoladas de urina de pacientes com candidúria em Iguatu-Ceará. Rev Bras Ana. Clin, v. 42, n. 3, p. 223-5, 2010.

13. HORN D. L. et al. Epidemiology and outcomes of candidemia in 2019 patients: data from the prospective antifungal therapy alliance registry. Clin Infect Dis, v. 48, n. 12, p. 1695-703. 2009.

14. LOCKHART, S. R. et al. Geographic distribution and antifungal susceptibility of the newly described species Candida orthopsilosis and Candida metapsilosis in comparison to the closely related species Candida parapsilosis. J Clin Microbiol, v. 46, n. 6, p. 2659-64, 2008.

15. MEDRANO, D. J. A. et al. Candidemia in a Brazilian hospital: the importance of Candida parapsilosis. Rev Inst Med Trop S. Paulo, v. 48, n. 1, p. 17-20, 2006.

16. MENEZES E. A. et al. Frequência e atividade enzimática de Candida spp. na cavidade oral de pacientes diabéticos do serviço de endocrinologia de um hospital de Fortaleza-CE. J Bras Patol Med Laborat, v. 43, n. 2 p. 241-4, 2007.

17. MIRHENDI, H. et al. Molecular screening for Candida orthopsilosis and Candida metapsilosis among danish Candida parapsilosis group blood culture isolates: proposal of a new RFLP profile for differentiation. J Med Microbiol, v. 59, n. 1, p. 414-20, 2010.

18. ODDS, F. C. et al. One year prospective survey of Candida bloodstream infections in Scotland. J Med Microbiol, v. 56, n. 1, p. 1066-75, 2007.

19. PATTERSON, T. F. Advances in the management of invasive mycoses. Lancet, v. 336, n. 9490, p. 101325, 2005.

20. PFALLER, M. A. et al. Candida bloodstream infections: comparison of species distribution and resistance to echinocandin and azole antifungal agents in Intensive Care Unit (ICU) and non-ICU settings in the SENTRY Antimicrobial Surveillance Program (2008-2009). Inter J Antimicr Agents, v. 38, n. 3 p. 65-9, 2011. 
21. RODRÍGUEZ, D. et al. Predictors of candidaemia caused by non-albicans Candida species: results of a populationbased surveillance in Barcelona, Spain. Clin Infect Dis, v. 16, n. 3, p. 1676-82, 2010.

22. SELLAMI, A. et al. Antifungal susceptibility of bloodstream Candida isolates in sfax hospital: Tunisia. Mycopathologia, v. 171, n. 2. p. 417-22, 2011.

23. SIVAKUMAR, V. G. et al. Use of CHROMagar in the differentiation of common species of Candida. Mycopathologia, v. 167, n. 1, p. 47-9, 2009.

24. TAVANTI, A. et al. Candida orthopsilosis and Candida metapsilosis spp. nov. to replace Candida parapsilosis groups II and III. J Clin Microbiol, v. 43, n. 1, p. 28492, 2005.

25. TAVANTI, A. et al. Genotyping of Candida orthopsilosis clinical isolates by AFLP reveals genetic diversity among independent isolates and strain maintenance within the same patient. J Clin Microbiol, v. 45, n. 5, p. 1455-62, 2007.
26. TAY, S. T.; NA, S. L.; CHONG, J. Molecular differentiation and antifungal susceptibilities of Candida parapsilosis isolated from patients with blood stream infections. J Med Microbiol, v. 58, n. 3, p. 185-91, 2009.

27. TORO, M. et al. Characterization of Candida parapsilosis complex isolates. Clin Microbiol Infect, v. 17, n. 1, p. 418-24, 2011.

28. TROFA, D.; GACSER, A.; NOSANCHUK, J. D. Candida parapsilosis, an emerging fungal pathogen. Clin Microbiol Rev, v. 21, n. 4, p. 606-25, 2008.

29. VAN ASBECK, E. C. et al. Candida parapsilosis fungemia in neonates: genotyping results suggest healthcare workers hands as source, and review of published studies. Mycopathologia, v. 164, n. 6. p. 287-93, 2007.

30. VASCONCELOS Junior, A. A.; CUNHA, F. A.; MENEZES, E. A. Chromogenic medium for direct susceptibility testing of Candida spp. isolated from urine. Mycopathologia, v. 172, n. 12, p. 125-30, 2011.

31. YONG, P. V. et al. Molecular identification of Candida orthopsilosis isolated from blood culture. Mycopathologia, v. 165, n. 2 , p. $81-7,2008$. 